\title{
Ética e pesquisa médica: princípios, diretrizes e regulamentações
}

\author{
Ethics and medical research: principles, guidelines, and regulations
}

\author{
Euclides Ayres de Castilho ${ }^{1}$ e Jorge Kalil ${ }^{2}$
}

\begin{abstract}
RESUM0
A questão da ética em pesquisa médica ganhou força no fim da Segunda Guerra Mundial, com o Código de Nuremberg. Nesse período, alguns casos ocorridos nos Estados Unidos da América contribuíram para evidenciar a necessidade de estabelecimento de regras e procedimentos em pesquisas médicas. Neste artigo, os Autores discorrem sobre alguns conceitos de ética e seus fundamentos filosóficos, enfatizando situações relacionadas à pesquisa. A ética em pesquisa médica apoia-se no tripé: aprovação pelos pares, consentimento do sujeito de pesquisa e sigilo dos dados individuais obtidos. Os Autores resumem as disposiç̧ões legais brasileiras para seguir regras e controlar o processo de aspectos éticos em pesquisas envolvendo seres humanos. Finalmente, abordam questões práticas do Termo de Consentimento Livre e Esclarecido decorrente de suas experiências na direção do Comitê de Ética e Pesquisa que analisa mais de 1.000 projetos por ano no Complexo do Hospital das Clínicas da Faculdade de Medicina da Universidade de São Paulo.
\end{abstract}

Palavras-chaves: Ética. Bioética. Pesquisa médica. Pesquisa clínica. Ética em pesquisa.

\begin{abstract}
The issue of ethics in medical research grew in importance at the end of the World War II, after the Nuremberg Code. In this period, some cases in the United States had demonstrated the need for the establishment of rules and procedures in medical research. In this article, the authors discuss some ethical concepts and their philosophical basis, stressing aspects related to research. Ethics in medical research is based upon three items: peer approaches, subject informed consent, and confidentiality of individual obtained data. The authors also summarize the Brazilian laws and directives to follow the precepts and to control the process of ethical issues in research with human participants. Finally, they approach practical questions of the Informed Consent Form as a consequence of their experiences analyzing more than one thousand research projects per year as members of the Internal Review Board of the University of São Paulo School of Medicine, São Paulo, Brazil.
\end{abstract}

Key-words: Ethics. Bioethics. Medical research. Clinical research. Ethics and research.

Os clássicos da Ética, Beauchamp e Childress ${ }^{1}$, base dos primeiros parágrafos deste artigo, afirmam que ética é um termo genérico para várias formas de se entender e analisar a vida moral. Algumas abordagens da ética são normativas (isto é, apresentam padrões de ações boas ou más), outras são descritivas (relatando aquilo em que as pessoas acreditam e como elas agem) e outras, ainda, analisam os conceitos e os métodos da ética ${ }^{1}$.

Ao tratar da questão o quê é moralidade?, pode-se ter a tentação de responder que a moralidade é uma teoria sobre 0 certo e 0 errado. Todavia, as palavras ética e moralidade não devem ser confinadas a contextos teóricos. Teoria ética e filosofia moral são os termos apropriados para se referir à reflexão filosófica sobre a natureza e a função da moralidade. 0 propósito de uma teoria é o de aumentar a clareza, a ordem sistemática e a precisão dos argumentos nas nossas reflexões sobre a moralidade. 0 termo moralidade se refere a convenções sociais sobre 0 comportamento humano certo ou errado, convenções tão largamente partilhadas que formam um consenso comum estável (embora, usualmente incompleto), enquanto a ética é um termo geral referente tanto à moralidade como à teoria ética1.

Algumas abordagens da ética são normativas. A resposta que procura responder à questão - Quais normas gerais para a orientação e avaliação da conduta devem ser moralmente

1. Departamento de Medicina Preventiva da Faculdade de Medicina da Universidade de São Paulo, São Paulo, SP e Comitê de Ética em Pesquisa do Complexo do Hospital das Clínicas da Faculdade de Medicina da Universidade de São Paulo, São Paulo, SP. 2. Departamento de Clínica Médica da Faculdade de Medicina da Universidade de São Paulo, São Paulo, SP e Comitê de Ética em Pesquisa do Complexo do Hospital das Clínicas da Faculdade de Medicina da Universidade de São Paulo, São Paulo, SP. Endereço para correspondência: Dr. Euclides Castilho. Deptº de Medicina Preventiva/HC/FM/USP. Av. Dr. Arnaldo 455, 01246-903 São Paulo, SP. Tel: 5511 3066-7444

e-mail: castil@usp.br

Recebido para publicação em 10/11/2004

Aceito em 18/3/2005 
aceitas e por quê razões? é uma ética normativa geral. A tentativa de descobrir as implicações de teorias gerais para formas específicas de conduta e julgamento moral é geralmente chamada de ética prática, embora muitas vezes seja equivocadamente denominada ética aplicada. 0 termo prático se refere ao uso da teoria ética e de seus métodos de análise para examinar problemas morais, práticas e políticas em várias áreas, inclusive nas políticas públicas e nas profissões ${ }^{1}$, daí, por exemplo, o Código de Ética Médica².

Além da ética normativa, há mais duas grandes classes de ética não-normativa. Tem-se a ética descritiva, que é a investigação fatual do comportamento e das crenças morais. Essa utiliza técnicas científicas para estudar como as pessoas raciocinam e agem. Já a metaética envolve a análise da linguagem, dos conceitos e dos métodos do raciocínio na ética. Nela se discutem, por exemplo, os sentidos de termos tais como: certo; obrigação; virtude; princípio; justificação; deveres e responsabilidades. Vale dizer que elas se entrelaçam, e portanto, não se justifica estabelecer distinções nítidas entre ética prática e ética normativa, assim como não se deve distinguir a ética normativa da metaética de modo radical ${ }^{1}$.

Uma teoria ética bem desenvolvida proporciona uma estrutura no interior da qual os agentes podem refletir sobre a aceitabilidade das ações e avaliar os juízos e 0 caráter morais. Teoria na ética possui as seguintes referências: 1) reflexão e argumentação abstratas; 2) reflexão e argumentação sistemáticas; 3) um corpo integrado de princípios coerentes e bem-formados. Existem vários tipos de teoria ética, baseados: 1) nas consequiências - 0 utilitarismo; 2) na obrigação - 0 kantismo; 3) na virtude - a ética do caráter; 4) nos direitos - 0 individualismo liberal; 5) na comunidade - 0 comunitarismo; 6) nos relacionamentos - a ética do cuidar; 7) nos casos - a casuística; 8) nos princípios e na moralidade comum. Assim, a ética (bioética) incorpora conflitos teóricos de complexidade considerável, onde os aspectos mais gerais - princípios, regras etc.- e os mais específicos - sentimentos, percepções, julgamentos etc.- devem ser ligados na deliberação moral, levando à uma ética plural ${ }^{16}$.

Zoboli diz que na Introdução da segunda edição da Enciclopédia de Bioética, 0 termo bioética édefinido como o estudo sistemático das dimensões morais, incluindo a visão, a decisão, a conduta easnormas dasciências da vida eda saúde, utilizando metodologias éticas num contexto interdisciplinar ${ }^{12}$.

Apesar dos importantes escritos antigos (desde a época de Hipócrates), medievais e modernos sobre 0 cuidado com a saúde, somente por volta do meio do século $\mathrm{XX}$, surgiu 0 primeiro documento de caráter internacional, com normas para pesquisa médica com seres humanos. 0 Código de Nuremberg ${ }^{11}$, datado de 1947, foi preparado por médicos estadunidenses visando dar subsídios aos juizes do Tribunal de Nuremberg para os julgamentos dos chamados crimes contra a humanidade cometidos em pesquisas médicas conduzidas nos campos de concentração $0^{13412}$.

É oportuno destacar que ao menos três casos excepcionais mobilizaram a opinião pública norte-americana e mundial para a questão do controle social nas pesquisas envolvendo seres humanos: 1) em 1963, três médicos, com aprovação do Diretor Clínico de um hospital judeu para enfermos com doenças crônicas, em Brooklyn, Nova Iorque, injetaram, por via subcutânea, células cancerosas viva em 22 pacientes debilitados, sem avisá-los ou aos familiares que tais células estavam sendo usadas a título de experimentação para mensurar a capacidade dos seus organismos rejeitarem células estranhas; 2) entre 1950 e 1970, em outro hospital daquela cidade, injetaram vírus de um tipo de hepatite em crianças com deficiência mental, visando a estudar a infectividade do vírus e a fisiopatologia da enfermidade; 3) de 1940 a 1972, no Tuskegee Study, em Alabama, EUA, cerca de 400 negros, a maioria analfabeta, com sífilis foram seguidos sem qualquer tratamento, visando a estabelecer a história natural da sífilis, apesar do surgimento em larga escala da penicilina, em 1945. Esse fato só foi descoberto em 1972 .

A observação dos princípios éticos implica avaliar, entre outros aspectos, os seguintes referenciais fundamentais para pesquisa envolvendo seres humanos. 0 Respeito à Autonomia - tendo surgido, inicialmente, com referência à autogestão ou ao autogoverno das cidades independentes gregas, o termo autonomia estendeu-se aos indivíduos, abrangendo os direitos de liberdade, privacidade, escolha individual, liberdade da vontade, ser o motor do próprio comportamento e pertencer a si mesmo. Exemplos típicos incluem as seguintes regras: 1) dizer a verdade; 2) respeitar a privacidade dos outros; 3 ) proteger informações confidenciais; 4) obter consentimento para intervenções nos pacientes; 5) quando solicitado, ajudar os outros a tomar decisões importantes. Portanto, a pesquisa envolvendo seres humanos deve sempre tratá-los em sua dignidade, respeitá-los em sua autonomia e defendê-los em sua vulnerabilidade. Não-maleficiência - este princípio determina a obrigação de não infligir dano intencionalmente. Ele está intimamente ligado com a máxima primum non nocere - acima de tudo (ou antes de tudo) não causar danos. Trata-se, desta maneira, da garantia de que danos previsíveis serão evitados. Beneficência - não é apenas necessário tratar o indivíduo como autônomo, mas também tem-se que contribuir para seu bemestar. Além da compaixão, bondade, caridade, altruísmo, amor, humanidade, 0 princípio da beneficência, em pesquisa, deve ser visto de modo que inclua todas as formas de ação que tenham 0 propósito de beneficiar outras pessoas. Deve-se proceder a uma ponderação entre riscos e benefícios, tanto atuais como potenciais, individuais ou coletivos, buscando 0 máximo de benefícios e 0 mínimo de danos e riscos. Justiça - o princípio da justiça engloba equidade, merecimento (o que é merecido) e prerrogativa (aquilo a que alguém tem direito). Desse modo, o princípio da justiça implica um tratamento justo, eqüitativo e apropriado, levando-se em consideração aquilo que é devido às pessoas. Segundo esse princípio, uma pesquisa deve ter relevância social com vantagens significativas para os sujeitos da pesquisa e minimizarão do ônus para os sujeitos vulneráveis, garantindo a igual consideração dos interesses envolvidos, não perdendo 0 sentido de sua destinação sociohumanitáriaa ${ }^{13412}$.

Além do citado Código de Nuremberg ${ }^{11}$, em nível internacional, têm-se como diretrizes e normas para pesquisas 
em seres humanos, a Declaração de Helsinque ${ }^{10}$, aprovada em assembléia da Associação Médica Mundial, em 1964. ADeclaração de Helsinque mantém esse nome, mesmo após revisões realizadas em diferentes sítios: Tóquio, em 1975; Veneza, em 1983; Hong Kong, em 1989, Sommerest, em 1996 e Edimburgo, em 2000. Em 1981, surge um documento elaborado pela Organização Mundial da Saúde (OMS) e pelo Conselho de Organizações Internacionais de Ciências Médicas (COICIM), intitulado Diretrizes Internacionais Propostas para a Pesquisa Biomédica em Seres Humanos com atualizações em 1993 e $2002^{34}$.

Na condução de uma pesquisa médica, em que um ser humano é o sujeito da pesquisa, temos que atentar para todos estes conceitos éticos. Pragmaticamente, baseia-se em ter princípios para avaliação ética de um projeto, a saber: 1) consentimento do sujeito; 2) manutenção da privacidade das informações do sujeito; 3) aprovação pelos pares e pela comunidade. A aprovação pelos pares avalia a relevância da questão científica, a relação entre o benefício da informação que será obtida com a pesquisa e 0 risco do sujeito, e a qualidade científica da proposta para responder as questões levantadas.

No Brasil, em 1988, o Conselho Nacional de Saúde (CNS) elaborou uma norma sobre ética em pesquisa médica - a Resolução n-01/88 do CNS. Este documento mescla aspectos éticos das pesquisas com questões e aspectos de biossegurança e de vigilância sanitária. Este fato, segundo alguns estudiosos ${ }^{4}$, explica a não implantação da resolução na medida desejada. A atual Constituição das diretrizes e normas regulamentadoras de pesquisa envolvendo seres humanos, no nosso País, é a Resolução no 196/96 do CNS ${ }^{9}$ e as resoluções complementares ${ }^{9}$ : a Resolução n 251/97 que normatiza as pesquisas com novos fármacos, medicamentos, vacinas e testes diagnósticos; a Resolução no 292/99 referente à pesquisa com cooperação estrangeira; para as pesquisas conduzidas na área de reprodução humana tem-se a Resolução no 303/00; a Resolução nํㅜ 304/00 refere-se às pesquisas com povos indígenas e a recente Resolução Complementar n⿳0 340/04 diz respeito à área de genética humana. A Comissão Nacional de Ética em Pesquisa (CONEP) é uma instância colegiada, de natureza consultiva, deliberativa, normativa, educativa, independente e vinculada ao Conselho Nacional de Saúde ${ }^{4}$.

Após a resolução 196/96, foram criados os Comitês de Ética em Pesquisa (CEPs) em todo o País com o objetivo de examinar as questões éticas em pesquisas com seres humanos, em que os três princípios acima mencionados são avaliados ${ }^{4}$.

ACONEP insiste exaustivamente no Termo de Consentimento Livre e Esclarecido (TCLE). Esse consentimento, surge nos EUA com a denominação de consentimento informado ou consentimento pós-informação. A CONEP entende 0 consentimento como livre por não poder haver nenhum tipo de limitação a influenciar a vontade e a decisão do sujeito da pesquisa, e esclarecido na medida em que se considera que 0 compromisso com 0 sujeito da pesquisa não é apenas 0 de informar, mas o de esclarecer.

Na elaboração do TCLE, o pesquisador deve procurar a efetiva informação ao sujeito de pesquisa para assegurar 0 seu direito de escolha. Deve-se ter em mente que poderá haver conflitos de interesse com 0 patrocinador da pesquisa (por ex. indústria farmacêutica), com a instituição de pesquisa (faculdade ou hospital) ou com o próprio pesquisador. Há vários casos relatados na literatura médica destes conflitos de interesse implicando problemas éticos importantes. Há, também, que se levar em consideração as diferenças culturais entre povos em um estudo multicêntrico internacional e sobretudo em minorias étnicas (por exemplo, população indígena) incluídos no estudo. Para tal, o TCLE deve ser escrito em termos acessíveis ao sujeito, e contemplar toda informação pertinente à pesquisa. Ele deve ser apresentado por indivíduo treinado e ser confidencial. Com a evolução da pesquisa, pode haver necessidade de o TCLE ser modificado, a informação renovada ou, em suma, ser reconsiderada a qualquer momento. Tudo isto para prover integral autonomia ao sujeito da pesquisa. Deve-se evitar ,sobretudo a ambigüidade, esconder riscos inerentes à pesquisa, ou ser dirigido aos pares que analisarão à proposta. Sua redação não merece ser feita visando à proteção do pesquisador, de instituição ou de patrocinador. Devem, ainda, estar claramente especificados os possíveis desconfortos, os riscos e os possíveis benefícios; como o paciente poderá obter continuidade se caso venha a se beneficiar do tratamento e como será indenizado ou tratado por problemas decorrentes da pesquisa. O sujeito deverá estar seguro da privacidade de todas informações. 0 pesquisador deverá deixar claro como procederá à informação em casos de incapacidade mental (crianças ou adultos com retardo mental), clínica ( pacientes inconscientes) ou culturais ( por exemplo, indígenas).

ACONEP postula que não poderá haver pagamento para que um sujeito participe da pesquisa sendo sua adesão voluntária. No entanto, poderá haver ressarcimento de despesas ou de interrupção de ganhos advindos do trabalho. Estas questões têm que estar claramente delineadas.

ACONEP preconiza, também, que os estudos clínicos devem ser controlados com o melhor tratamento atualmente existente. Estudos com placebo devem ser evitados e só serão aceitos em casos excepcionais.

0 TCLE é ainda hoje a razão principal de devolução de protocolos para modificações ( cerca de $25 \%$ das nãoaprovações, quando da primeira análise, de projetos analisados pela CAPPesq (Comissão de Ética pa Análise de Projetos de Pesquisa do Complexo HC-FMUSP). Também, é responsabilidade dos CEPs auditarem a execução da pesquisa e revisarem os termos do TCLE baseados nos resultados da pesquisa.

Atualmente, no Brasil, o profissional médico, em qualquer atividade, dever ser conhecedor da Carta Magna de 19887, em especial da Seção II do Capítulo II do Título VIII que dispõe sobre saúde, e , obviamente, do Código de Ética Médica². № que tange àqueles interessados em pesquisas em seres humanos, devem estar familiarizados com os já citados documentos nacionais e internacionais e com as referidas Resoluções do Conselho Nacional de Saúde. Para a área de pesquisa, vale destacar, ao menos 3 artigos: Do Código de Ética Médica (Resolução do Conselho Federal de Medicina no 1246 de 8/01/1988) ${ }^{2}$ : Art. 2ํㅜ - 0 alvo de toda a atenção do médico é a saúde do ser humano, em benefício da qual deverá agir com o máximo de zelo e 0 melhor de sua capacidade; Art. 460- é vedado ao médico efetuar qualquer 
procedimento médico sem 0 esclarecimento e 0 consentimento prévios do paciente ou de seu responsável legal, salvo em iminente perigo de vida; Art. 123ํ- é vedado ao médico realizar pesquisa em ser humano, sem que este tenha dado consentimento por escrito, após devidamente esclarecido sobre a natureza e consequiência da pesquisa. Para obtenção de autorização para realização de pesquisa clínica com medicamentos e produtos para a saúde, tem-se que obedecer às disposições da Resolução no 219/04 da Agência Nacional de Vigilância Sanitária (ANVISA) ${ }^{8}$. Finalmente, em termos de responsabilidade penal, merecem destaque 2 artigos do Título I - Dos crimes contra a pessoa Parte Especial do Código Penal5: Art. 129. Ofender a integridade corporal ou a saúde de outrem: Pena - detenção, de três meses a um ano; e Art.132. Expor a vida ou a saúde de outrem a perigo direto e iminente: Pena - detenção, de três meses a um ano, se 0 fato não constitui crime mais grave.

Como Hipócrates disse:

"A vida é curta

E muito longo o caminho a percorrer

As oportunidades são passageiras

A experiência traiçoeira

E a avaliação difícil"

Assim, para se obter a esperada integridade na pesquisa clínica, não há uma fórmula, mas um comportamento ético.

\section{REFERÊNCIAS BIBLIOGRÁFICAS}

1. Beauchamp TL, Childress JF. Princípios de ética. Edição Brasileira. Edições Loyola, São Paulo, 2002.

2. Código de Ética Médica. Available from URL: http://www.cfm.org.br.

3. Emanuel EJ, Crouch RA, Arras JD, Moreno JD, Grady C. Ethical and regulatory aspects of clinical research. The Johns Hopkins University Press, Baltimore, 2004.

4. Hosne WS. A regulamentação de pesquisa com seres humanos como instrumento de controle social. In: Fortes PAC, Zoboli ELCP (eds) Bioética e Saúde Pública. Edições Loyola, São Paulo, p. 95-111, 2003.

5. Lopes MAR. Código Penal. Editora Revista dos Tribunais, São Paulo, 1998.

6. Oliveira F. Bioética: uma face da cidadania. Editora Moderna, São Paulo, 2002.

7. Oliveira J. Constituição da República Federativa do Brasil. Promulgada em 5 de outubro de 1988. Editora Saraiva, São Paulo, 1996.

8. Resolução 219/04 da Agência Nacional de Vigilância Sanitária. Available from: http://www.anvisa, gov.br, 2004.

9. Resoluções 196/96, 251/97, 292/99, 303/00 e 304/00 do Conselho Nacional de Saúde. Available from URL: http://conselho.saude.gov.br.

10. The Declaration of Helsinki. The World Medical Association. In: Emanuel Ej, Crouch RA, Arras JD, Moreno JD, Grady C ( eds) Ethical and regulatory aspects of clinical research. The Johns Hopkins University Press, Baltimore, p. 30-32, 2004.

11. The Nuremberg Code. Nuremberg Military Tribunal. In: Emanuel EJ, Crouch RA, Arras JD, Moreno JD, Grady C (eds) Ethical and regulatory aspects of clinical research. The Johns Hopkins University Pres, p. 29, 2004.

12. Zoboli ELCP. Referências de análise em Bioética: 0 desafio de traçar sua interface com a Saúde Pública. In: Fortes PAC, Zoboli ELCP (eds) Bioética e Saúde Pública, Edições Loyola, São Paulo, p. 25-34, 2003. 